\title{
Notas sobre a ideia de improvisação musical em Nietzsche
}

\author{
Fernando R. de Moraes Barros*
}

Resumo: O propósito geral do presente texto consiste em introduzir o sentido e o alcance que noção de improvisação musical pode adquirir no filosofar nietzschiano, e, em especial, no assim chamado período de maturidade de seu itinerário intelectual. Tencionase indicar que tal ideia assume uma função reguladora em seu pensamento, possibilitando lançar uma intensiva luz sobre o seu legado e enfatizar, sobretudo, o caráter pluralista e dinâmico deste último.

Palavras-chave: improviso musical, poesia conceitual, natureza.

* Universidade de Brasília (UNB), Brasília, Distrito Federal, Brasil.

ORCID https://orcid.org/0000-0002-1045-4570

Correio eletrônico: frbarros76@gmail.com 
Barros, F. R. M.

Foi bem cedo que a ideia de "improvisação" atraiu os holofotes de Nietzsche. Já em seu último ano ginasial, então aluno da icônica escola Pforta, tal noção se lhe oferecia como algo particularmente instigante. Tanto é assim que, com a irmã, ele chega a comentar:

Ontem, um improvisador [Improvisator], Professor Bärmann, entreteu-nos maravilhosamente; uma personalidade assaz amável, de espírito muito refinado e sagaz. Levantamos-lhe alguns temas, sendo que, dentre eles, um nos pareceu admirável: "sobre o difícil aprendizado de matemática"; acerca do qual ele discorreu com primor (...) Mas, o que significa improvisar? Nossa própria vida assemelha-se, com frequência, aqui e acolá, a uma improvisação poética, e basta usar apenas um pouco de fantasia para senti-la enquanto tal. Lisbeth, Lisbeth, onde está a chave para esse pensamento? Sabes o que é uma esfinge? (6 de dezembro de 1863. KSB 1.269)

Que o vínculo entre matemática e fantasia é mais umbilical do que meramente analógico, eis o que salta aos olhos de quem percorre, por exemplo, os Estudos lógicos de F. A. Lange, livro que Nietzsche terminaria por manter sempre à mão em sua biblioteca e em cujo último capítulo - intitulado, não por acaso, "Espaço, tempo e número" - lê-se: "Os teoremas da geometria e as características essenciais da lógica formal adquirem sua validade apriorística exclusivamente com o auxílio da fantasia, seja se valendo de uma figura demonstrativa ou não". O sentido de improvisação que irá ganhar forma e conteúdo em Nietzsche não se refere, porém, às possíveis relações entre axiomas e determinadas intuições espácio-temporais - as quais fariam as vezes, no aludido contexto, de imagens originárias tanto das grandezas contínuas quanto das grandezas discretas ${ }^{2}$. É no âmbito artístico,

1F. A. Lange, 1877, p. 131.

2 "Domínios importantes da nova álgebra resultam justamente da observação de imagens espaciais. Tal como, por exemplo, a teoria combinatória, sobre cujos resultados se baseiam tantas outras coisas. Aqui, as letras, alinhadas em série e ordem, oferecem-se em substituição aos objetos em geral, e, aliás, de objetos particulares, assim como, na lógica, expusemos a soma de dados objetos por meio de círculos e retângulos. É próprio à representação espacial a capacidade de extrair, no interior da grande e abrangente síntese do múltiplo, unidades cada vez menores dos mais diversos tipos com

130 | Cad. Nietzsche, Guarulhos/Porto Seguro, v.42, n.1, p. 129-144, janeiro/abril, 2021. 
e, em especial, na esfera da música, que tal termo irá adquirir uma função seminal em sua obra. E há motivos suficientes para tanto. Afinal de contas, Nietzsche também foi um músico. Decerto não o mais proficiente desua geração, mas sem dúvida um intérprete ardoroso e um melodista nato - tendo iniciado o estudo responsável do piano aos nove anos de idade e se dedicado, com afinco, ao célebre método de Albrechtsberger, ${ }^{3}$ sabia aplicar responsavelmente os princípios contrapontísticos e as regras gerais de estruturação diatônica. Familiarizado com a obra de Schumann e bem informado acerca da movimentada harmonia de seu século, o filósofo alemão sempre esteve atento à assinatura sonora que lhe era contemporânea, prenhe de dissonâncias, acordes de sétima sem preparação e construtos cromáticos acintosamente inquietantes. Mas, antes de mais nada, ele foi um exímio improvisador, tornando-se inclusive afamado por isso. "Desde sua infância", relembra-nos Georges Liébert, "ele tinha uma predileção especial pelas improvisações"4. Dando primazia ao livre desabrochar dos arcos melódicos e aos mais finos contornos ad libitum, sua execução, sempre inventiva, impactava amiúde àqueles que dela se colocavam à escuta, mostrando-se, por fim, como diz Curt Paul Janz, "muito expressiva e cheia de nuances, ocasionando um efeito sugestivo" .

É claro que, em termos de sua definição explicativa, a noção mesma de improvisação musical pode e deve ser ampliada em direção a outras paragens hermenêuticas no interior do filosofar nietzschiano, conduzindo-nos a um horizonte teórico-especulativo mais vasto e para além do teclado do piano. Assim é que, durante o período de juventude de seu itinerário intelectual, marcado pela

facilidade e segurança. O espaço é, por isso, a imagem primordial não apenas das grandezas contínuas, senão que também das grandezas discretas, e os números pertencem a essas últimas, sendo que dificilmente conseguiríamos pensar o tempo senão que como um contínuo.” (F. A. Lange, 1877, p.141)

3 Cf. J. G. Albrechtsberger, 1790.

4 G. Liébert, 2012, p.24.

5P. C. Janz, 1976, Vorwort, p. IX.

Cad. Nietzsche, Guarulhos/Porto Seguro, v.42, n.1, p. 129-144, janeiro/abril, 2021. | 131 
Barros, F. R. M.

assim chamada "metafísica de artista", o filósofo alemão faz intervir uma figura de improvisador que será decisória à mediação entre a esfera dramático-musical, sensitiva desde a raiz, e o âmbito da representação propriamente artística, instância estética mais figurativa e imageticamente tangível. Isso porque caberá ao próprio improvisador a tarefa de tornar operatória a confluência, trágica por excelência, entre o coro visionário (um "espectador" encantado) e a polimórfica força generativa contida no livre canto dionisíaco - o qual, nascido da improvisação, jacta-se em se assumir idealmente como uma espécie de drama primordial. A esse propósito, dir-se-á: "Eis os dois pontos de partida distintos da tragédia grega: o coro, que contempla uma visão, e o enfeitiçado improvisador dionisíaco [der verzauberte dionysische Improvisator]. $\mathrm{O}$ coro fornece apenas a imagem viva e o improvisador, por seu turno, o drama (Nachlass/ FP 1871, 9[104], KSA 7.311)

Atuando como um elo de consolidação entre o intensivo plano das emoções e as figurações cênicas mais delineáveis, o improviso surge e se justifica, pois, como um vetor expressivo de experiências subjetivas poderosamente pervasivas. E não é de admirar que, alguns anos depois, após ter publicado todas as suas Considerações extemporâneas, Nietzsche termine por identificar o improviso musical com uma forma mais genuína e pregnante de prazer. Irmanado a um tipo particularmente íntimo de satisfação, o prazer no improviso parece pressupor, sobretudo, uma escala avaliativa deveras pessoal e marcadamente hierarquizada. A esse respeito, lê-se:

Quando ordeno as coisas conforme o grau de prazer que elas causam, eis o que se me coloca acima de tudo: uma improvisação musical no momento oportuno; aí então a escuta de coisas específicas de Wagner e Beethoven, e, depois, algumas ideias engenhosas ocorridas em caminhadas antes do almoço (Nachlass/FP 1876, 23[57], KSA 8.423.) 
Além disso, se nos for facultado considerar o ato mesmo de escrever como resultado epifenomênico de uma refinada organização artística das mais recuadas e telúricas correntes pulsionais, a improvisação musical também pode ser compreendida como uma tonificante fonte de inspiração redacional, voltada ao estabelecimento de estratégias argumentativas desprendidas e recursos estilísticos mais autônomos, hauridos de uma espiritualização "musicalizada" de nossas bases somáticas. E, sob tal ótica, não seria um exagero dizer que o inteiro desenvolvimento estilístico do filosofar nietzschiano decorreria, em rigor, de uma tática improvisatória de cunho efetivamente musical. É Nietzsche mesmo que, desde o início, impõe essa exigência estilística a si próprio. Tanto é assim que, ao colega Carl Von Gersdorff, escreve:

Antes de mais nada, aquilo que deve ser novamente desencadeado em meu estilo são certos espíritos vívidos; preciso aprender a jogar com eles tal como toco o teclado do piano, mas não apenas tal como interpreto as peças que já sei de cor, senão que também livres fantasias [freie Phantasieen], executadas o mais livremente possível, porém, sempre com lógica e beleza (6 de abril de 1867. KSB 1.210).

Anos depois, aliás, tal orientação tornar-se-á uma marca distintiva de seus textos, os quais surgirão a partir de uma autocompreensão musicalmente orientada, que considera a linguagem, $a b$ ovo, como um refinamento escalonado de certos instintos e afetos. A esse respeito, lê-se de modo lapidar:

O que há de mais compreensível na linguagem não é a palavra ela mesma, senão que o som, a força, a modulação e o tempo com o qual uma série de palavras é dita - em suma, a música por detrás das palavras, a afetividade por trás de tal música, a pessoa atrás de tal afetividade; portanto, tudo aquilo que não pode ser escrito (Nachlass/FP 1882,3[1]296, KSA 10.89) 
Barros, F. R. M.

Todavia, emoldurada como um recurso imediatamente aplicável e assimilável a processos infra-conscientes, intelectualmente resgatáveis apenas mediante sublimações graduais das correntes instintivas à base de nossa corporeidade, a modalidade enunciativa afetivamente germinada e retroalimentada pela música, dir-se-ia, talvez, corre o risco de submergir nas caudalosas e turvas águas do não-cognitivismo, quase sempre identificado, com demasiada pressa, a incontidos e desenfreados arroubos emocionais. Mas, mesmo fazendo jus a essa interpretação, já de si comprometida com certos prejuízos, não deveríamos render-nos, aqui, tão fácil e açodadamente a uma chave de leitura antirrealista. Afinal, até mesmo em Kant, para quem a música, salvo como pura divisão do tempo, nunca foi uma candidata apropriada para exemplificar o ajuizamento estético em sua gratuidade e pureza formal - como mero "jogo das sensações", a arte dos sons seria incapaz de se proteger, digamos, dos conteúdos sensoriais obtidos via afecções, razão pela qual não estaria apta a gerar um prazer formado exclusivamente pela representação de sua própria forma ${ }^{6}$-; enfim, mesmo nesse registro, circunscrito ao analítico prisma kantiano, as ditas "fantasias" musicais não são totalmente destituídas de uma livre beleza - a própria ausência de um tema específico ou texto tornaria o impromptu preferível às chamadas belezas aderentes, as quais jamais poderiam ser completamente independentes e desinteressadas. Sobre as belezas independentes que nada representam, Kant comenta: “Também se pode contá-las como da mesma espécie aquilo que, na música, denominam-se fantasias (sem tema), inclusive a inteira música sem texto." ${ }^{97}$, a bem dizer, sequer precisaríamos ir tão longe. Mesmo na rarefeita ambiência do jazz moderno, marcado pela profusão de deslocamentos, extravios e

6Donde o famigerado e condenatório veredito proferido pelo autor da Crítica do juízo: "dentre as belas artes, a música ocupa o último lugar (...) porque joga simplesmente com sensações” (I. Kant, 1974, p. 269. [B 221]).

7I. Kant, 1974 p. 146. (B 49)

134 | Cad. Nietzsche, Guarulhos/Porto Seguro, v.42, n.1, p. 129-144, janeiro/abril, 2021. 
imprecisões, a improvisação não é indício ou sinônimo de um cego e desgarrado laissez-faire sônico, emblema caricato daquilo que conta vigorar, sem mais, como irracional e randômico. É claro que os ditos standards de jazz, temas que foram objetos de diferentes versões e subsequentes apropriações, não dependem, para adquirir validação, de partituras univocamente determinadas por seus autores, a serem interpretadas e apreendidas como signos sonoros subjetivamente adequados e sintaticamente inconfundíveis. A título de veículos auxiliares, as chamadas lead sheets - transcrições de arranjos que exibem, de forma sintética, sugestões de direcionalidade e progressões harmônicas norteadoras - limitam-se, em geral, delineamento de acordes de sustentação e padrões melódicos, de sorte que, como bem nos lembra Daniel Feige, "quando transcrevemos uma performance de jazz, não estamos realmente transcrevendo uma partitura musical pertencente à exibição de uma dada obra, mas, antes do mais, capturando um evento espácio-temporal concreto"8. Contudo, isso nem de longe implica que as improvisações jazzísticas sejam, per se, indiscerníveis em termos da classe de suas execuções, impermeáveis, por assim dizer, a todo tipo de transitividade, reflexividade e simetria entre o que se lê notacionalmente e o que se escuta sobre o palco. Aqui, a peculiaridade estaria no fato de que, à diferença dos protocolos semânticos que regulam a produção musical tradicional, a peça é significada apenas à medida em que seu curso é reflexionantemente reorganizado, assumindo uma "significação" que depende, por retroação, do que ainda está por ser improvisadamente executado: "Aquilo que o improvisador toca adquire seu sentido específico apenas à luz do que estará consumado posteriormente."9 Quanto a isso, poder-se-ia paradoxalmente dizer que cada nota se investe de um significado musical somente sob a égide de todas aquelas notas que ainda deverão ser tocadas ou omitidas - ou, antes ainda, por se

8D. M. Feige, 2014, p.73

9D. M. Feige, 2014, p.77.

Cad. Nietzsche, Guarulhos/Porto Seguro, v.42, n.1, p. 129-144, janeiro/abril, 2021. | 135 
Barros, F. R. M.

tratar justamente de improvisos, pelos sons que não serão ecoados conforme imaginávamos que seriam.

É certo que o repertório de sons atinente ao período romântico, e, sobretudo, às progressões utilizadas na segunda metade do século XIX, também é repleto de inflexões rítmicas, apojaturas e digressões harmônicas, flertando, não raro, com o limiar mesmo do pós-tonalismo. Fazendo confluir o emprego sistemático de pedais, acordes diminutos e aumentados, tal sonoridade resulta, muitas vezes, em ordens intervalares divergentes, sendo algo corriqueiro, em tal período, encerrar uma canção com um acorde inesperadamente diferente daquele com o qual foi iniciada. Engana-se, porém, quem aqui vê apenas um gesto insistente e programático em glorificação à desarticulação tonal. Pois é certo ainda que, mesmo a sequência sonora mais imprevisível e imaginativa, ocasionada in loco e livremente em ação, envolve e pressupõe algum nível de concentração e aplicação dirigida, escolhas tímbricas e um mínimo controle técnico. Se consentimos em nos deixar embalar pela aparente inefabilidade e imponderabilidade de certas ocorrências sonoras não relacionais, é porque, em rigor, passamos aprazivelmente ao largo da intencionalidade e do premeditado desarranjo que as conduzem. É nesse sentido, aliás, que o autor de Humano, demasiado humano escreve, rechaçando as brumas supersticiosas que costumam se adensar sobre a ideia de improvisação artística:

É do interesse dos artistas que haja uma crença em certas sugestões repentinas, o mesmo é dizer, nas assim chamadas inspirações; como se a noção mesma de obra de arte, de poesia, ou, então, do pensamento fundamental de uma dada filosofia despencasse do céu qual um raio da graça (...) mas a improvisação artística ocupa um lugar inferior em comparação aos pensamentos artísticos séria e diligentemente selecionados. Todos os grandes foram grandes trabalhadores, incansáveis não apenas na arte de inventar, senão que também no ato de rejeitar, rever, redimensionar e rearranjar (MA I/HHI I, 155, KSA 2.146) 
Por isso, sob a perspectiva nietzschiana, o mais acertado seria dizer que há, no fundo, dois tipos de improvisadores. De um lado, aqueles - os ditos "trabalhadores" - cujos poderes criativos se acham intimamente vinculados à compositiva marcha de feitura de suas obras e cuja diligência se revela indispensável ao sentido improvisatório atribuído a seus mais fantasiosos construtos. A estes, a improvisação seria fruto de um fazer artístico interpretativamente disciplinado, no seio do qual as atividades de criação e realização, para lançar mão aqui das palavras de Alessandro Bertinetto, "não apenas ocorrem ao mesmo tempo, senão que constituem uma e mesma ocorrência generativa."10 De outro, haveria aqueles que, rejeitando todo devir e abstraindo das consolidações diacrônicas à base de seus produtos, associam a improvisação a miraculosas centelhas geniais, introduzindo em suas obras, como dirá Nietzsche, "elementos de inquietude encantada, de desordem cegamente cativante (...) de sorte a fazercom que a alma do espectador ou do ouvinte termine por acreditar no surgimento inesperado da perfeição (MA I/HHI I, 145, KSA 2.141)".

Sem dúvida, a promessa de perfeição pode tornar os artefatos artísticos assaz atraentes. Em especial, se estes últimos estiveram amparados por imperiosas e, por vezes, despudoradas exigências metafísicas. Pois, embora o ato de ouvir, assim como o de ler, indique um desenvolvimento e refira-se a uma dada sucessão - a ação mesma de passar de um compasso a outro, ou, simplesmente, de se mover à próxima página livro adentro -, os movimentos de uma peça musical e os capítulos de uma obra literáriaco existem simultaneamente com a inteireza e completude da totalidade de que fazem parte. E ainda que a execução de uma determinada canção e a leitura de um certo poema se desdobrem sempre numa espécie de "aqui e agora", permanecendo, sob tal angulo, ínsitos à sua localização - quer seja na biblioteca, quer seja na sala de concerto -, o mesmo não valeria, porém, à obra propriamente dita, a qual, como dirá Maria Reicher a

10 A. Bertinetto, 2013, p.87 
propósito, "não podemos de modo nenhum localizar espacialmente"ll . Poesias e melodias já acabadas persistem, enquanto objetos abstratos, em vários lugares ao mesmo tempo, enraizando-se, na prática, em local nenhum, independentemente de seus leitores e ouvintes. Desse ponto de vista, uma determinada performance fatalmente constituirá, à força da bilocação da obra da qual se sabe um exemplo, uma forma singular de instanciação, sem jamais se oferecer em substituição, digamos, ao seu protótipo original. E, por esse viés, se não for falar mais do que o necessário, a relação que vigora entre um objeto musical tipificado e as vozes e instrumentos que o "atualizam" não seria muito distinta da relação que se estabelece, grosso modo, entre os números e os numerais que os instanciam. Descobertos e não propriamente inventados, entidades numéricas e "entes" musicais teriam então sempre existido, para além do paradigma físico-temporal que modula tanto os objetos psíquicos, quanto os ditos objetos materiais. E, por essa senda, o famoso acorde de Tristão, assim como as leis de Newton ou o teorema de Pitágoras, estariam apenas à espera de quem os revelassem ao mundo. Subsistindo antes mesmo que Wagner tomasse consciência de seus pensamentos, o aludido acorde perduraria mais e mais, mesmo se ninguém voltasse a executá-lo. Não por acaso, Peter Kivy dirá a esse respeito:

A mim me parece bastante plausível, considerá-lo uma descoberta de Wagner em vez de sua invenção, embora, é claro, a descoberta de tal acorde tenha exigido um trabalho maior do que o de uma vida inteira. Isso tampouco estorva a imaginação metafísica de retratar o acorde de Tristão - aquela relação específica de quatro tons - comoalgo que preexiste à sua descoberta, à maneira de um objeto platônico ${ }^{12}$.

Mas, afinal, que outro ímpeto nos impeliria a hipostasiar uma discrepância de fundo entre o objeto musical e sua materialização

11 M. E. Reicher, 2019, p.19.

12 P. Kivy, 2004, p.97.

138 | Cad. Nietzsche, Guarulhos/Porto Seguro, v.42, n.1, p. 129-144, janeiro/abril, 2021. 
"audível", por assim dizer, senão que a velha vontade de verdade zelosamente acalentada pela tradição filosófica? Mais até. O que nos levaria a denegar um poder criativo e emancipatório ao compositor, cujas melodias não passariam de meros achados, senão que a crença num criador impermeável a toda mudança, único capaz de proceder ex nihilo? E talvez seja aqui, nesse patamar reflexivo extramundano, que a noção de improvisação acabe por assumir sua face propriamente nietzschiana, fazendo ressurgir uma visão processual de mundo a contrapelo daquilo que tenciona valer como permanente e eterna obra de arte. Essa abordagem nos permitiria, por exemplo, para o elevado rendimento da meditação estética sobre Nietzsche, lançar uma luz penetrante sobre o termo "Spielwerk", operador de que o autor d'Agaia ciência $§ 109$ se serve para favorecer uma espécie de "deificação da natureza" - efigiando o mundo como um gigante mecanismo musical ou realejo apto a cuidar de si mesmo, dando conta de suas próprias "sonoridades", por assim dizer:

A ordenação astral em que vivemos constitui uma exceção; essa ordenação e a razoável duração por ela determinada possibilitou, uma vez mais, a exceção dentre as exceções: a formação do orgânico. O caráter global do mundo, em contrapartida, é caos em toda sua eternidade, mas não no sentido de uma falta de necessidade, senão que de uma falta de ordem, divisão, forma, beleza, sabedoria e seja lá quais outros nomes que se queira dar aos nossos antropomorfismos estéticos. Ajuizado à luz de nossa razão, os lances de dados malogrados constituem, com distância, a regra; as exceções tampouco são o alvo almejado, sendo que a inteira caixa-demúsica [Spielwerk] repete eternamente suas cantigas, que jamais devem ser chamadas de melodia (FW/GC 109, KSA 3.468).

A imagem é desconcertante, entre outras coisas, porque o realejo ou caixa-de-música é um aparato musical mecânico operado à manivela, cujos foles entoam cantigas predefinidas, de sorte que, em termos de desempenhos improvisatórios, talvez não houvesse outro instrumento mais antipódico à livre criação. Mas convém ressaltar, 
Barros, F. R. M.

ainda que muito sucintamente, o pano de fundo que cruza e integra tal exposição. Talhado com magistral requinte exegético, o texto articulase em torno de contendas cosmológicas intrincadas e carregadas de sutis planos investigativos, os quais, para resumir bastante, trazem ao primeiro plano as consequências teóricas mais paroxísticas da recepção dos dois modernos princípios da termodinâmica - debate mormente imantado à problemática relativa à dispersão geral de energia e à morte térmica do universo. Implicando passar em revista posicionamentos provenientes das concepções organicista e panfisicista do cosmos, a ponderação condensa e externa os anseios questionadores de Nietzsche a respeito de vertentes teleológicas assentadas, explícita ou implicitamente, numa ordenação moralizante e finalista do mundo. Avesso às modalidades metafísicas de valoração que concebem o universo como um ser vivo, o objetivo central do filósofo alemão consiste, em linhas gerais, em denunciar os não-ditos e preconceitos antropomórficos de que tais visões globais se achariam fatalmente eivadas. Para aquilo que aqui nos importa, cumpre frisar o aceite de que o recurso ao mecanicismo, como bem lembra Paolo D'Torio, em sua minuciosa reconstituição de tal passagem - guiada pela tentativa nietzschiana de justificar cientificamente a doutrina do eterno retorno -, funcionaria mais como um aliado útil ou uma arma de derrubada do que como uma tomada de partido ou alinhamento conceitual em sentido estrito. Aqui,o pensador parece mesmo

dar primazia à mecânica sobre o organicismo e, efetivamente, a visão mecânica é para Nietzsche seguramente a mais plausível e menos antropomórfica que o organicismo. Mas, na realidade, face às duas imagens dominantes nas discussões cosmológicas de sua época, a máquina e o organismo, Nietzsche quer restituir à natureza seu caráter polimorfo, proteiforme, não estruturado, caótico, cuja teoria do eterno retorno, enquanto princípio não-teológico e não-teleológico, é a sanção mais forte. ${ }^{13}$

13 P. D’Iorio, 2006, p. 95-96.

140 | Cad. Nietzsche, Guarulhos/Porto Seguro, v.42, n.1, p. 129-144, janeiro/abril, 2021. 
Desdivinizada, a caixa-de-música cosmológica é, assim como o improviso musical, desprovida de um télos previamente significado. Antropomorficamente desidratada, sua atuação não é efeito de um músico-causa, senão que um fluxo sonoro contínuo que sempre vem a ser, ainda que, à luz de nossa racionalidade, seus foles ressoem estranhezas e formas nas quais não nos reconhecemos - motivo pelo qual suas cantigas jamais poderiam ser propriamente chamadas de melodia.

Poder-se-ia objetar, quiçá, que tal ilustração seria apenas mais uma maneira de aplicar, metafisicamente às avessas, expedientes poéticos e imagéticos com vistas à caracterização de uma totalidade que suplanta hipóteses "objetivas" de interpretação do mundo e da natureza - isto é, em que pese os esforços do filósofo alemão para impedir a essencialização ou divinização das forças naturais, tratarse-ia, aqui, no fundo, tão somente de mais um modo de embaralhar as funções lítero-musicais da linguagem com a própria metafísica, usando enunciados não científicos ou "pseudo-proposições" para elucidar questões efetivamente teoréticas. A nós nos parece, porém, que isso equivaleria a ignorar, em detrimento de uma reflexão cuidadosa sobre o legado nietzschiano, o fato de que o autor d'A gaia ciência tinha completa noção do uso pós-kantiano do termo "poesia conceitual" [Begriffsdichtung] - em especial, do sentido que lhe fora atribuído por F. A. Lange, sob o influxo do qual iniciamos estas nossas breves observações e que a esse propósito escreve: "Só podemos poetizar sobre uma verdade absoluta depois de nos termos convencido da relatividade de todo conhecimento" $"$. Porque ganha seus contornos a partir do caráter constitutivamente pluralista do conhecimento, a ideia de um improviso musical da natureza jamais poderia significar, em Nietzsche, um improviso musical $d a$ natureza. E não é outra coisa que ele tenciona esclarecer ao colega Paul Deussen, quando a este escreve ainda no período de juventude:

14F. A.Lange,1897, p.9. 
Barros, F. R. M.

O domínio da metafísica, e, por conseguinte, o âmbito da verdade "absoluta" foi necessariamente alinhado à poesia e à religião (...) Assim, para alguns, a metafísica pertence à esfera das necessidades da alma e constitui, essencialmente, uma edificação; por outro lado, ela é uma arte, a saber, a arte da poesia conceitual; cumpre todavia observar que, seja como arte, seja como religião, a metafísica nada tem a ver com a assim chamada "verdade ou o ser em si” (do final de abril/início de maio de 1868. KSB 1.269).

Ora, uma vez posicionada no âmbito da edificação e inoculada, via circunscrição pluralista do conhecimento, contra a ambição teórica de descerrar verdades incontestáveis, a "Spielwerk" nietzschiana se insere num domínio distinto daquele que em que se trava, ao modo dogmático, as modernas querelas cosmológicas, desonerandose da missão de descrever estados "reais" de coisas. E não só. Pois, mesmo que o célebre dístico de Carnap tenha ampla razão de ser - conforme o qual os "metafísicos são músicos sem qualquer habilidade musical"15 - teríamos tanto mais motivos para nos colocar à escuta de Nietzsche, o qual, sendo um talentoso improvisador, não se limitaria apenas a exprimir uma relação emocional com o ambiente circundante e tampouco poderia ser colocado na mesma conta de metafísicos autocomplacentes com a falta de musicalidade. Encarando o inafugentável drama da finitude e a fabilidade de todo existir sem recorrer a um ideal transcendente de perfeição artística, ele se diferenciaria, porém, do improvisador da vida, que "faz lembrar aqueles mestres da improvisação musical, aos quais tambémo ouvinte gostaria de atribuir uma infabilidade divina da mão" (FW/GC 303, KSA 3.541). Sem medo de malograr e sem levar tão a sério seus próprios desejos e planos, o filósofo abismado na arte do improvisar é aquele que, ao piano - e não só ao piano -, diz: "não sei se devo agradecer mais aos meus fracassos do que a algum êxito (...) Sei mais da vida, porque com muita frequência já estive perto de perdê-la; e, por isso mesmo, recebo mais da vida que todos vós!" (FW/GC 303, KSA 3.542).

15R. CARNAP, 1931, p. 240.

142 | Cad. Nietzsche, Guarulhos/Porto Seguro, v.42, n.1, p. 129-144, janeiro/abril, 2021. 
Notas sobre a ideia de improvisação musical em Nietzsche

\section{Remarks on the idea of musical improvisation in Nietzsche}

Abstract: The present text aims at introducing the meaning and the scope that the notion of musical improvisation may acquire within Nietzsche's thought - especially in the light of thehis latter writings. It also intends to show that such idea performs a regulatory function within his thought and allows us, at the same time, to shed a bright light on his legacy, serving first and foremost to emphasize its pluralistic and dynamic character

Keywords: musical improvisation, conceptual poetry, nature.

\section{Referências}

BERTINETTO, A. Musical ontology: a view through improvisation. In: Cosmo. Comparative studies in modernism,Turim, n.2, 2013.

CARNAP, R. Überwindung der Metaphysik durch logische Analyse der Sprache. In: Erkenntnis. Springer, n. 2, 1931, p. 219-41.

D'IORIO, P. O eternoretorno. Gênese e interpretação. Tradução de Ernani Chaves. In: Cadernos Nietzsche. São Paulo, n. 20, 2006, pp.69-114.

JANZ, P. C. Der Musikalische Nachlass. Basel: Bärenreiter, 1976.

KANT, I. Kritik der Urteilskraft. Editadapor Wilhelm Weischedel. Frankfurt am Main: Suhrkamp, 1974.

KIVY, P. Platonism in music: a kind of defense. In: LAMARQUE, P.; OLSEN, S. H. (org.). Aesthetics and the philosophy of art. The analytic tradition. An anthology. Oxford: Blackwell, 2004.

LANGE, F. A. Logische Studien. Ein Beitrag zur Neubegründung der Formalen Logik und der Erkenntinisstheorie. Iserlohn: J. Baedeker Verlag, 1877.

. Einleitung und Kommentar zu Schillers Philosophischen Gedicthen. Bielefedl/Leipzig: Velhagem\&Klafing, 1897 
Barros, F. R. M.

LIÉBERT, G. Nietzsche et la musique. Paris : Puf, 2012.

NIETZSCHE, F. Sämtliche Briefe. Kritische Studienausgabe. Org. por Giorgio Colli/ MazzinoMontinari. Berlin/New York: De Gruyter, 1986. . Sämtliche Werke. Kritische Studienausgabe. Org. por Giorgio Colli/ MazzinoMontinari, Berlin/ New York, 1999.

REICHER, M. E. Werk und Autorschaft: Eine Ontologie der Kunst. Münster: Mentis Verlag, 2019. 